\title{
Our common vision
}

\author{
Sustainability research provides significant insights into the ways people and the natural world are connected. It is \\ the mission of Nature Sustainability to showcase this kind of understanding to help its way into policy, solutions and \\ everyday debates.
}

\begin{abstract}
n 1987, the World Commission on Environment and Development published its iconic report Our Common Future, also known as the Brundtland report (http:// go.nature.com/2kxZARA), recognizing the key ideas uniting sustainability scholars and practitioners - the realization that the socioeconomic and biophysical realities of our world are connected, and that a deep understanding of such a connection should guide decisions about our future development trajectories. Since then, words such as sustainable and sustainability gained prominence in the language of politicians, businessmen and professionals, campaigners, educators and lay people. But the interpretation of those words has been continuously debated and, to some at least,
\end{abstract} sustainability remains an ambiguous concept that is hard to grasp.

Sustainable and sustainability both derive from the Latin term sustinēre, which means 'to hold up from below', implying 'to support', 'to maintain' or perhaps even 'to restrain'. So, if we envisage a system in which people and nature are mutually connected, then sustainability means finding ways to keep that system healthy and ongoing. Sustainability experts appreciate the inherent complexity of the human-natural system and work with it. Their view is clear: it is only by gaining a better understanding of such complexity that we can enlighten our actions and ensure that the system will last.

The Brundtland report acknowledged the success of past development pathways that led, for example, to improved quality of life and higher schooling rates in many developing countries. But it also clearly highlighted the failures. Development had not been sustainable and a radical change in the way we organize our lives was, and still is, urgently needed. Today, we realize that this kind of shift cannot be achieved without engagement and commitment from all sectors of society, and without an agreed and binding policy framework that unites all societal actors. In this spirit, the international debate about sustainability intensified at the turn of the twenty-first century and culminated in September 2015 with the adoption by 193 United Nations

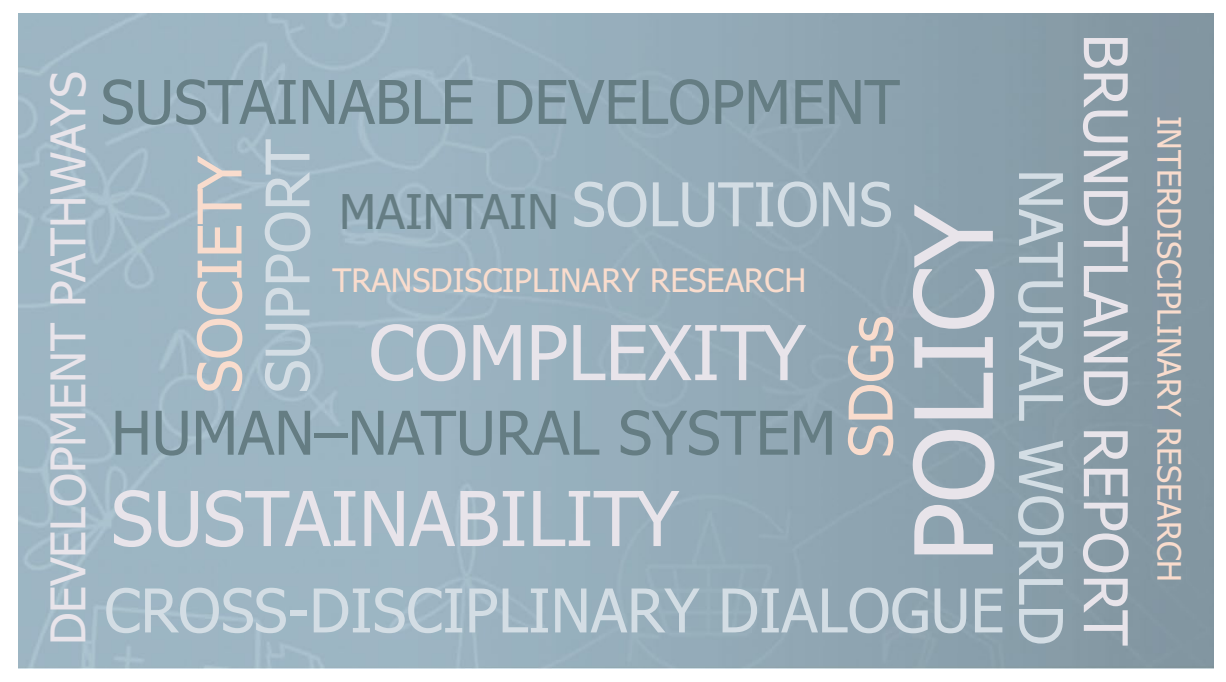

member states of the 17 Sustainable Development Goals (SDGs) to be achieved by 2030 (http://go.nature.com/2kW1xsY).

The research community has a fundamental role to play in advancing the SDG agenda, and more generally our understanding of the intricate relationships between humans and the natural world. Academic work on sustainability-relevant questions began before the Brundtland report; over time, different models and conceptual frameworks, and new methods, have been developed, and a growing number of research articles have been published. Yet most sustainability-oriented research has not received the scholarly recognition it deserves, as we in the Nature family have found out through our conversation with relevant experts in recent years. Scholars from across all domains voiced one message: that a journal dedicated entirely to sustainability research, able to reach across disciplines to feature different perspectives and facilitate cross-disciplinary dialogue; inclusive of different kinds of research all elevated to one level of prestige; showcasing first-class scholarship on the broadest set of issues relevant to sustainability, is absolutely needed. With the launch of Nature Sustainability, we intend to meet this need.

To make significant advances in our understanding of human-nature interactions requires insights from a huge variety of research domains, both from their own specific angle and as part of interdisciplinary and transdisciplinary work. All such advances will find their home in Nature Sustainability. But that is not all. Under the sustainability umbrella, some research will be oriented to find actionable solutions, while other work will try to understand problems; some research, but not all, will have users' needs at its core; not all research will involve complexity, but some will. And again, we at Nature Sustainability welcome this variety.

Our remit is to transcend disciplinary constraints highlighting relationships, problems, policies and potential solutions. Our ultimate goal is to go beyond featuring knowledge to featuring insight that will catalyse understanding and wise action. While admittedly ambitious, this goal has long informed the work of those who already consider themselves sustainability scholars, as well as those who have arrived there from more traditional beginnings. Featuring this work and uniting and providing voice to this community is, ultimately, our common vision.

Published online: 8 January 2018

https://doi.org/10.1038/s41893-017-0020-x 